\title{
Estimation of Radiation Dose during Diagnostic X-Ray Examinations of Newborn Babies and 1-Year-Old Infants
}

\author{
A. Brindhaban C.U. Eze \\ Department of Radiologic Sciences, Faculty of Allied Health Sciences, Kuwait University, Sulaibikhat, Kuwait
}

\author{
Key Words \\ Entrance surface dose - Paediatric X-ray examinations . \\ Radiation risk
}

\begin{abstract}
Objective: It was the aim of this study to investigate radiation doses for commonly performed paediatric X-ray examinations (skull, chest, abdomen and pelvis) in public hospitals in Kuwait in order to establish national reference or guidance dose levels. Materials and Method: Exposure factors used for six commonly performed Xray examinations - antero-posterior (AP) chest, lateral chest, AP abdomen, AP skull, lateral skull and AP pelvis - were obtained from various hospitals, and entrance surface doses (ESD) were measured using a Victoreen model 660 survey meter. Effective doses $(E)$ and the corresponding risk of developing fatal malignancies were calculated using published conversion factors and methods recommended by the International Commission of Radiological Protection for newborn babies to 1-year-old infants. Results: The range of ESD values was 26$668 \mu \mathrm{Gy}$ for newborn babies and $40-700 \mu \mathrm{Gy}$ for 1 -yearold infants. The range of $E$ values was about $4-150 \mu \mathrm{Sv}$ for the two age groups. The risk of developing long-term stochastic effects due to radiation exposure ranges between 0.6 and 23.4 per million. Conclusion: The range of ESD values, E values and risk of development of fatal
\end{abstract}

malignancies obtained in this study can be used as a guide for the risk-benefit analysis of an X-ray examination for newborn babies and 1-year-old infants. Tube voltages used for these examinations should be kept above $60 \mathrm{kV}$, whenever possible, to minimise the radiation dose.

Copyright (C) 2006 S. Karger AG, Basel

\section{Introduction}

Establishment of guidance levels or reference doses for paediatric patients undergoing diagnostic X-ray examinations have been of concern to various national and international organisations involved in radiation measurement, monitoring and safety. Radiation protection agencies in many countries, including Australia [1], the United Kingdom [2], the United States of America [3] and New Zealand [4], have set reference dose levels for commonly performed diagnostic X-ray examinations. These reference values of entrance surface (or skin) dose (ESD) have been arrived at based on the 3rd quartiles of the distributions of dosimetric data from nation-wide surveys of 5-year-old patients [5, 6]. These values are used as guidance levels regardless of the age of the paediatric patients. However, this may not be suitable for newborn babies and 1-year-old children whose average body weight is approximately $50 \%$ of an average 5-year-old child, and

\section{KARGER}

Fax +4161306 1234

E-Mail karger@karger.ch

www.karger.com
(C) 2006 S. Karger AG, Basel

1011-7571/06/0154-0260\$23.50/0

Accessible online at:

www.karger.com/mpp
Dr. A. Brindhaban

Department of Radiologic Sciences, Kuwait University

PO Box 31470

Sulaibikhat 90805 (Kuwait)

Tel. +965 498 4898, Fax +965 483 3662, E-Mail ajit@hsc.edu.kw 
would lead to overexposure of the infants. The International Commission of Radiological Protection (ICRP) uses the terms 'diagnostic reference levels' and 'guidance levels for patient dose' $[7,8]$ to indicate guidance levels of radiation dose during diagnostic $\mathrm{X}$-ray examinations.

The risk for paediatric patients of developing longterm biological effects following exposure to ionising radiation is higher than that for adults because their cells, tissues and organs have a higher radiosensitivity, and they have a longer time to live, thereby enabling the effects to manifest. In addition, the chances of repeat examinations are higher with paediatric patients due to improper immobilisation and less effective communication during the examinations. The European Commission (EC) [9] states that 'radiation exposure in the first 10 years of life is estimated to have a risk about 4 times greater than exposures incurred at 30-40 years of age for some detrimental effects'. Publishing reference or guidance levels will aid medical professionals to take the necessary steps to minimise the chances of radiation-induced late effects, while at the same time carrying out sufficient radiographic examinations to aid medical diagnosis.

Although radiation doses during diagnostic X-ray examinations of the adult patients have been extensively studied [10-15], few studies have focused on radiation doses for newborn babies and 1-year-old infants. These studies have shown that there is a wide range of ESD values for the same paediatric X-ray examination [3, 5, 6, 16-20]. Radiation doses during diagnostic X-ray examinations of paediatric patients have not been studied in Kuwait, and reference or guidance levels have not been set. Therefore, the aim of this study was to conduct a dose survey of commonly performed X-ray examinations of newborn babies and 1-year-old infants in six public hospitals in Kuwait in order to facilitate the establishment of national reference or guidance dose levels for patients in these age groups.

\section{Materials and Methods}

Age Groups and Technique Factors

Antero-posterior (AP) chest, lateral chest, AP abdomen, AP skull, lateral skull and AP pelvis X-ray examinations of newborn babies and 1-year-old infants were selected for the study. The radiographic technique factors used for the examinations of the 'standard patients' of the two age groups were obtained from the Departments of Radiology of six public hospitals (Al Sabah, Al Amiri, Mubark Al-Kabir, Al Razi, Ibn Sina and Farwaniya) where paediatric examinations are carried out routinely. The height, head, trunk thickness and weight of the 'standard patients' were assumed to correspond to the values published in literature [15]. The X-ray tube voltage, tube-current time product, focus-to-film distance, use of Bucky/grid and the approximate collimator settings (field size) for these X-ray examinations were obtained from exposure charts. At Al Sabah hospital, where automatic exposure control (AEC) devices were used for some radiographic examinations, an indication of the tube-current time product value selected by the AEC device for a standard or average patient was used for dose measurements.

\section{Exposure Measurements and Dose Calculations}

Free-in-air exposures were measured using a Victoreen model 660 digital radiation survey meter with a 6.3 -cm-diameter and 0.4-cm-thick ionisation chamber at $40 \mathrm{~cm}$ from the tube focus for each combination of tube voltage and tube-current time product used for each projection of the two age groups. The accuracy of Victoreen is $\pm 5 \%$ and the energy response is $\pm 10 \%$ for 20 $660 \mathrm{keV}$. Free-in-air exposures were converted to ESD using the following equation:

$$
E S D=X \times F_{D a, X} \times f_{B S} \times f_{C a l} \times f_{D}
$$

where $\mathrm{X}$ is the exposure measured by the ionisation chamber in units of Roentgen, $f_{\mathrm{Da}, \mathrm{X}}\left(8.7 \mathrm{mGy} \mathrm{R}^{-1}\right)$ is the conversion factor between exposure and absorbed dose in air, $f_{\mathrm{BS}}$ is the backscatter factor, $f_{\text {Cal }}(1.037)$ is the ionisation chamber calibration factor for the range of X-ray energies used in this study and $f_{\mathrm{D}}$ is the inverse square law correction factor for the difference in the position where $\mathrm{X}$ was measured and the actual location of the patient's skin on the entrance X-ray field.

The ionisation chamber calibration factor was obtained from the manufacturer (Victoreen LLC, Cleveland, Ohio, USA) of the unit for X-ray beams at $65 \mathrm{kV}$ with a half-value layer (HVL) of $2.4 \mathrm{~mm} \mathrm{Al}$ equivalence. The distance from tube focus to entrance skin of the patient and the backscatter factor for each projection were taken from previous reports [21, 22]. The accuracy of each tube voltage value for the projection on each X-ray unit was evaluated using the RMI Model 230 Digital kV Meter (Radiation Measurements Inc., Middleton, Wisc., USA). The first HVLs for two tube voltage settings, between 60 and $80 \mathrm{kV}$, from each X-ray unit were established using the routine method. These values were then used to estimate the total filtration of each X-ray unit using the Institute of Physics and Engineering in Medicine data set [23]. The average of the two total filtration values was used for dose calculations.

The range and mean ESD of the distribution among the hospitals were calculated for each projection of the two age groups. The effective dose (E) values for all the projections were calculated for each age group using data sets from previous reports [21, 22], tube voltage, total filtration and the computer programme Child Dose [24]. This programme used published conversion factors [21, 22] for calculating organ dose and $\mathrm{E}$ values from measured values of voltage, total filtration and ESD. For the effective dose calculations, the dose to 'remainder organs' was calculated by taking a mass-weighted mean dose to 10 remainder organs as recommended by the ICRP [7]. Subsequently, the range and mean E values of the distribution for each radiographic projection of the age groups were established. The risk of patients developing fatal malignancies during their life time due to these examinations was also calculated using an absolute risk factor [25] of $0.15 \mathrm{~Sv}^{-1}$ for both age groups. 
Table 1. Tube voltage ranges, ESD values, E values and risk of developing fatal malignancies for various $\mathrm{X}$-ray examinations for newborn babies

\begin{tabular}{|c|c|c|c|c|c|c|c|c|}
\hline \multirow[t]{2}{*}{ Examination } & \multirow[t]{2}{*}{$\mathrm{n}$} & \multirow{2}{*}{$\begin{array}{l}\text { Tube voltage } \\
\mathrm{kV}\end{array}$} & \multicolumn{3}{|c|}{ ESD, $\mu \mathrm{Gy}$} & \multicolumn{2}{|l|}{$\mathrm{E}, \mu \mathrm{Sv}$} & \multirow{2}{*}{$\begin{array}{l}\text { Risk per } \\
\text { million }\end{array}$} \\
\hline & & & range & mean & $\mathrm{EC}[9]$ & range & mean & \\
\hline AP chest (NB) & 7 & $73-52$ & $32-176$ & 74 & 80 & $8-40$ & 18 & $1.2-6$ \\
\hline Lateral chest (NB) & 6 & $69-52$ & $38-190$ & 78 & 200 & $8-22$ & 12 & $1.3-3.3$ \\
\hline AP abdomen (NB) & 8 & $73-50$ & $26-378$ & 146 & 900 & $8-110$ & 42 & $1.2-16$ \\
\hline AP skull (NB) & 6 & $66-55$ & $82-382$ & 194 & 1,500 & $6-26$ & 14 & $0.9-3.9$ \\
\hline Lateral skull (NB) & 4 & $63-52$ & $62-248$ & 116 & 1,000 & $4-14$ & 6 & $0.6-2.1$ \\
\hline AP pelvis (NB) & 9 & $70-52$ & $78-668$ & 270 & 200 & $16-156$ & 62 & $2.4-23.4$ \\
\hline
\end{tabular}

The tube voltage values are given in the range of maximum to minimum in order to reflect the increase in ESD, E and risk with decreasing voltage. NB = Non-Bucky technique.

Table 2. Tube voltage ranges, ESD values, E values and risk of developing fatal malignancies for various X-ray examinations for 1-year-old patients

\begin{tabular}{|c|c|c|c|c|c|c|c|c|}
\hline \multirow[t]{2}{*}{ Examination } & \multirow[t]{2}{*}{$\mathrm{n}$} & \multirow{2}{*}{$\begin{array}{l}\text { Tube voltage } \\
\mathrm{kV}\end{array}$} & \multicolumn{3}{|c|}{$\mathrm{ESD}, \mu \mathrm{Gy}$} & \multicolumn{2}{|l|}{$\mathrm{E}, \mu \mathrm{Sv}$} & \multirow{2}{*}{$\begin{array}{l}\text { Risk per } \\
\text { million }\end{array}$} \\
\hline & & & range & mean & EC [9] & range & mean & \\
\hline AP chest (NB) & 7 & $81-52$ & $40-144$ & 64 & 100 & $8-28$ & 12 & $1.2-4.2$ \\
\hline Lateral chest (NB) & 7 & $90-57$ & $62-284$ & 132 & 200 & $8-32$ & 16 & $1.2-4.8$ \\
\hline AP abdomen (NB) & 7 & $81-52$ & $98-700$ & 396 & 900 & $24-152$ & 84 & $3.6-22.8$ \\
\hline AP skull (NB) & 4 & $73-55$ & $128-692$ & 292 & 1,500 & $4-16$ & 7 & $0.6-2.4$ \\
\hline Lateral skull (NB) & 4 & $70-53$ & $108-456$ & 208 & 1,000 & $4-12$ & 6 & $0.6-1.8$ \\
\hline AP pelvis (NB) & 8 & $73-52$ & $96-456$ & 216 & 200 & $12-38$ & 31 & $1.8-5.7$ \\
\hline
\end{tabular}

The tube voltage values are given in the range of maximum to minimum in order to reflect the increase in $\mathrm{ESD}, \mathrm{E}$ and risk with decreasing voltage. $\mathrm{NB}=$ Non-Bucky technique.

\section{Results}

The number of different radiographic technique factors, the range of tube voltage values used for each X-ray examination or projection, the range, mean and the EC reference value of ESD, together with $\mathrm{E}$ values and the risk (per million) of fatal malignancies due to exposure to ionising radiation are given in tables 1 and 2 . The voltage values, which influence the ESD and E values, revealed a wide range among the six hospitals. The lowest voltage was $50 \mathrm{kV}$ for the AP abdomen X-ray examination of the newborn babies and the highest was $90 \mathrm{kV}$ used for the lateral chest X-ray examination of the 1-year-old infants. ESD values obtained for all the $\mathrm{X}$-ray examinations have a wide range: $78-668 \mu \mathrm{Gy}$ was obtained for pelvic examination of newborn babies and 90-700 $\mu \mathrm{Gy}$ for the abdomen examination of 1-year-old patients. The ratios of maximum to minimum ESD for most of the X-ray examinations for both age groups were between 3 and 10 .

Higher mean ESD values were recorded for the newborn babies compared with the 1-year-old infants for AP chest and AP pelvis X-ray examinations. The risk associated with each X-ray examination is also presented in tables 1 and 2. The pelvic and abdominal examinations resulted in the highest risk, in the order of about 23 per million population.

The mean ESD values for all examinations were equal to or lower than the EC reference values except for the AP pelvis examination of the newborn babies. However, the maximum ESD values for AP chest and AP pelvis examinations of both age groups and for the lateral chest X-ray of the 1-year-old infants were much 
higher than the EC reference values. It is evident from the tables that the E values for 1-year-old infants tended to be slightly less than those for the newborn babies when similar ESD values for the same X-ray examination were recorded.

\section{Discussion}

The wide range of ESD values for each examination and the maximum to minimum ratios less than 10 can be attributed to the use of different X-ray units, exposure factors, image receptors and, most importantly, to variations in patient size within an age group, as previously reported [16, 17, 26, 27]. However, the ratio for the AP abdomen examination of the neonates was 14.5. In this study, the high-end ESD value corresponds to the lowest voltage value $(50 \mathrm{kV})$, used for any radiographic examination of the neonates and 1-year-old patients, and has resulted in a ratio greater than 10 . Although the ESD values presented here are generally lower than the EC reference values, they are higher than values reported in a UK study [28]. However, Armpilia et al. [28] represent doses during X-ray examination of patients in a neonatal baby care unit and may not represent the majority of the newborn and 1-year-old patients due to the differences in birth weight and/or patient size. Our results indicate that there is room for dose reduction during paediatric X-ray examinations.

Higher E values for newborn babies for the same examinations with similar ESD values is expected because the critical organs with specific weighting factors [7] for the calculation of $\mathrm{E}$ are likely to be closer to the primary radiation beam than in the case of 1-year-old infants. For the same reasons, the pelvic and abdominal X-ray examinations resulted in higher risk than any other X-ray examination. To avoid irradiation of these organs, protective shielding should be used to minimise scattered radiation produced external to the patient's body reaching these organs. It is also known that individuals with certain diseases such as ataxia telangiectasia are at increased risk of carcinogenesis from ionising radiation, and there is other evidence of inhomogeneous distribution of susceptibility to carcinogenesis from ionising radiation [25].

The risks of patients developing fatal malignancies were calculated using the highest risk factors for paediatric patients from the ICRP [7] and should therefore be regarded as the upper limits. The $\mathrm{E}$ values for all $\mathrm{X}$-ray examinations of both age groups were comparable with $\mathrm{E}$ values from a similar survey in Australia [16]. The tube voltage values measured by the digital voltage meter were within $10 \%$ of the values set on the unit for all X-ray units used in this study. There was also good agreement $( \pm 5 \%)$ between the total filtration values calculated using the HVL values obtained at the two different tube voltage settings for all X-ray units. The overall uncertainty in the calculation of ESD and $\mathrm{E}$ is estimated to be $\pm 20 \%$, including contributions from voltage measurements, total filtration estimation and ESD calculations.

It should be noted that the range of tube voltages used for various examinations presented in tables 1 and 2 is given in maximum to minimum values in order to reflect the increase in ESD, E and risk with decreasing voltage. In practice, adequate optical density on radiographs is achieved by the combination of exposure factors such as tube voltage and tube-current time product. It is well known that the lower the voltage used for any examination, the higher the tube-current time product required to achieve adequate optical density on the film and hence the higher the radiation dose for the patient. The selection of voltages used for any examination depends on the anatomy being imaged and the contrast required on the final image. As the voltage is increased, the contrast between different tissues on the final image diminishes, and hence, the voltage used should provide a balance between contrast and patient dose.

The reasons for recording high ESD values in some Xray examinations in this study can be attributed to the use of low voltage and high tube-current time product combinations. Negative correlation between HVL of the $\mathrm{X}$-ray beam and ESD during X-ray examinations of premature infants has been reported [29]. The HVL can be raised by increasing either the voltage of the X-ray beam or the total filtration of the X-ray unit. One particular survey [20] found that the use of tube voltages less than $60 \mathrm{kV}$ for paediatric examinations contributed to higher doses. This study confirms the EC recommendation that the use of tube voltages less than $60 \mathrm{kV}$ should be avoided for X-ray examinations of paediatric patients. The imaging facilities using less than $60 \mathrm{kV}$ should investigate the possibilities of increasing the tube voltages used and thereby suitably reducing the tube-current time product value. Increasing the voltage is more convenient than changing the filtration and can be done easily by the technologist. This should be investigated as a possible dose reduction technique where high ESD values are recorded. It has also been reported [30] that the use of computed radiography (CR) can significantly reduce the radiation dose without any apparent loss of image quality, and 
hence, CR should be used whenever possible. From the range of ESD values obtained in this study, we recommend that the mean ESD values for all six X-ray examinations, for the two age groups, be used as guide for a more comprehensive nationwide survey. Investigations should be carried out to establish modified exposure factors with CR systems in an effort to reduce the patient dose. As a first step, all imaging facilities should aim to achieve ESD and E values below the mean values presented in the tables and then further dose reduction techniques need to be explored.

The effective dose is a quantity that was introduced for radiation protection purposes in radiation workers. It is calculated [7] by the sum of radiation doses received by specific organs/tissues weighted by tissue weighting factors. However, the effective dose has been extensively used to report the risk of radiation exposure from medical examinations which involve ionising radiation [31]. The risk estimates presented in tables 1 and 2 were calculated using a common risk factor of $0.15 \mathrm{~Sv}^{-1}$ for both male and female patients and was obtained from the range of $0.10-0.15 \mathrm{~Sv}^{-1}$ for young children presented in the study of Roebuck [25], which was obtained from the ICRP [7]. However, some studies [32, 33] present different risk factors for male $\left(0.103 \mathrm{~Sv}^{-1}\right)$ and female $\left(0.12 \mathrm{~Sv}^{-1}\right)$ patients and use an average value of $0.11 \mathrm{~Sv}^{-1}$ for risk calculations from effective doses. The difference between using separate risk factors for male and female patients is small and the risk estimates presented here may be overestimated and can be considered as upper limits for both sexes.

The E values can also be calculated from the measurement of dose-area product (DAP) values for various X-ray examinations. Some studies [34, 35] have indicated that
E values obtained from DAP measurements represent a more accurate estimation of $\mathrm{E}$ compared with $\mathrm{E}$ values obtained from ESD measurements. This is mainly because the DAP takes into account the area of the patient's body which is irradiated and hence affects the number of organs irradiated. The ESD is measured at the centre of the X-ray field and does not include any information about the area irradiated. Although the EC recommends DAP measurements [36] because it is more practical in recording the entire examination and position of the patient in the X-ray beam is less important compared with ESD measurements, it also alerts to some disadvantages. In paediatric radiology, where small areas are irradiated, the DAP value can be small while absorbed organ doses are high due to the 'dose' part in DAP being high. This will underestimate E values obtained from DAP, and therefore, additional measurements such as skin dose are recommended for non-standard paediatric examinations. The DAP meters can be easily attached to the X-ray beam collimators and used for radiation dose monitoring during $\mathrm{X}$-ray examinations. This should be used, whenever possible, as an on-line dose audit so that the technologists and/or radiologists can recognise overexposures.

\section{Conclusion}

The range of ESD values, E values and risk for newborn babies and 1-year-old infants obtained in this study should be used as a guide by medical practitioners to carry out a risk-benefit analysis for the justification of an Xray examination before it is requested. Tube voltages used for these examinations should be kept above $60 \mathrm{kV}$, whenever possible, to minimise the radiation dose.

\section{References}

1 National Health and Medical Research Council: Recommendations for limiting exposure to ionising radiation. NHMRC Radiation Health Series 39. Australia, NHMRC, 1995.

2 National Radiological Protection Board: National protocol for patient dose measurements in diagnostic radiology. Chilton, UK, Dosimetry Working Party of the Institute of Physical Sciences in Medicine, NRPB, 1992.

3 Conference on Radiation Control Program Directors: Average patient exposure guides. CRCPD Publications 88(5); Kentucky, USA. CRCPD, 1988
4 National Radiation Laboratory: Code of safe practice for the use of X-rays in medical diagnosis. New Zealand NRL C5. Australia, NRL, 1995.

-5 Schneider K, Kohn MM, Ernst G: The derivation of reference dose values to chest $\mathrm{X}$-rays in paediatric radiography. Rad Prot Dosim 1998; 80:199-202.

6 Kohn MM, Moores BM, Schibilla H, Schneider K, Stender, H, Stieve FE, Teunen D, Wall B: European guidelines on quality criteria for diagnostic radiographic images in paediatrics. EUR 16261EN. Luxembourg, Luxembourg Official Publications of the European Communities, 1996.
7 International Commission on Radiological Protection: Recommendations of the International Commission on Radiological Protection - ICRP 60. Annals of ICRP 21. Oxford, Pergamon Press, 1990.

8 International Commission on Radiological Protection: Radiological protection and safety in medicine. Annals of the ICRP 26 (ICRP publication 73). Oxford, Pergamon Press, 1990.

9 European Commission: European guidelines on quality criteria for diagnostic radiographic images in paediatrics. European Commission EUR 161261 EN. Luxembourg, European Commission, 1996. 
10 Shrimpton PC, Wall BF, Jones DG, Fisher ES, Hillier MC, Kendall GM, Harrison RM: A national survey of doses to patients undergoing a selection of routine X-ray examinations in English hospitals. NRPB Report R200. Chilton, UK, National Radiological Protection Board, 1986.

11 Rueter FG, Conway BJ, McCrohan JL, Suleiman $\mathrm{OH}$ : Average radiation exposure values for three diagnostic radiographic examinations. Radiology 1990;177:341-345.

12 Serro R, Carreiro JV, Galvao JP, Reis R: Population dose assessment from radiodiagnosis in Portugal. Rad Prot Dosim 1992;34:65-68.

13 Williamson BDP, Poletti JL, Cartwright PH, Le Heron JC: Radiation dose to patients in medical diagnosis X-ray examinations in New Zealand. New Zealand NRL Report. Christchurch, NZ, National Radiation Laboratory, 1993/1.

- 14 Gallini RE, Belletti S, Berna V, Giugni U: Adult and children doses in standardised $\mathrm{X}$ ray examinations. Rad Prot Dosim 1992;43: 41-47.

15 Cardillo I, Boal T, Einsiedel P: Patient dose from chest radiography in Victoria. Australas Phys Eng Sci Med 1996;20:92-101.

16 Boal T, Cardillo I, Einsiedel P: Paediatric dose from diagnostic radiology in Victoria. Australas Phys Eng Sci Med 1998;21:57-67.

- 17 Perlmutter N, Arthur RJ, Belufti G, Cook V, Horwitz EA, Kramer P, Montague JP, Thomas PS, Schnider K: The quality criteria for diagnostic radiographic images in paediatrics. $\mathrm{Rad}$ Prot Dosim 1998;80:45-48.

18 Almen A, Mattson S: Dose distribution in children at chest radiography: Rad Prot Dosim 1995;57:463-467.
9 Schneider K: Evolution of quality assurance in paediatric radiology. Rad Prot Dosim 1995;57: 119-123.

-20 Schneider K, Fendel H, Bakowski C, Stein E, Kohn M, Kellner M, Schweighofer K, Cartagena G, Padovani R, Panzer W, Scheurer C, Wall B: Results of a dosimetry study in the European Community on frequent X-ray examinations in infants. Rad Prot Dosim 1992;43: 31-36.

21 Hart D, Jones DG, Wall BF: Normalised organ doses for paediatric X-ray examinations calculated using Monte Carlo techniques. NRPBSR279. Chilton, National Radiological Protection Board, 1996.

22 Hart D, Jones DG, Wall BF: Coefficients for estimating effective doses from paediatric $\mathrm{X}$ ray examinations. NRPB-R279. Chilton, National Radiological Protection Board, 1996.

23 Institute of Physics and Engineering in Medicine: Catalogue of diagnostic X-ray spectra and other data. IPEM Report 78. York, UK, IPEM, 1997.

24 Le Heron JC: Child dose: a user guide. Christchurch, National Radiation Laboratory, 1997.

25 Roebuck DJ: Risk and benefit in paediatric radiology. Pediatr Radiol 1999;29:637-640.

26 Montgomery A, Martin CJ: A study of the application of paediatric reference levels. $\mathrm{Br} \mathrm{J} \mathrm{Ra}-$ diol 2000;73:1083-1090.

27 Gogos KA, Yakoumakis EN, Tsalafoutas IA, Makri TK: Radiation dose considerations in common paediatric X-ray examinations. Pediatr Radiol 2003;33:236-240.
28 Armpilia CI, Fife IJA, Croasdale PL: Radiation dose quantities and risk in neonates in a special care baby unit. Br J Radiol 2002;75: 590-595.

29 Brindhaban A, Al-Khalifah K: Radiation dose to premature infants in neonatal intensive care units in Kuwait. Rad Prot Dosim 2004;111: 275-281.

- 30 Hufton AP, Doyle SM, Carty HML: Digital radiography in paediatrics: radiation dose considerations and magnitude of possible dose reduction. Br J Radiol 1998;71:186-199.

31 McCollough CH, Schueler BA: Calculation of effective dose. Med Phys 2000;27:828-837.

- 32 Mazonakis M, Damilakis J, Raissaki M, Gourtsoyiannis N: Radiation dose and cancer risk to children undergoing skull radiography. Pediatr Radiol 2004;34:624-629.

33 Robb JD: Estimates of radiation detriment in a UK population. NRPB-R260. Chilton, National Radiological Protection Board, 1994.

34 Yakoumakis E, Tsalafoutas A, Nikolaou D, Nazos I, Koulentianos E, Proukakis CH: Difference in effective dose estimation from dosearea product and entrance surface dose measurements in intravenous urography. $\mathrm{Br}$ Radiol 2001;74:727-734.

35 Le Heron JC: Estimation of effective dose to the patient during medical X-ray examinations from measurements of dose-area product. Phys Med Biol 1992;37:2117-2126.

36 European Commission: Guidance on diagnostic reference levels (DRLs) for medical exposures. Geneva, Switzerland, Director-General, Environment, Nuclear Safety and Civil Protection, 1999. 